\title{
GLIDERS AS A COMPONENT OF FUTURE OBSERVING SYSTEMS
}

Pierre Testor $^{(1)}$, Gary Meyers ${ }^{(2)}$, Chari Pattiaratchi ${ }^{(3)}$, ${\text { Ralf } \text { Bachmayer }^{(4)} \text {, Dan Hayes }}^{(5)}$, Sylvie Pouliquen ${ }^{(6)}$, Loic Petit de la Villeon $^{(6)}$, Thierry Carval ${ }^{(6)}$, Alexandre Ganachaud ${ }^{(7)}$, Lionel Gourdeau ${ }^{(7)}$, Laurent Mortier ${ }^{(8)}$, Hervé Claustre $^{(9)}$, Vincent Taillandier ${ }^{(9)}$ Pascale Lherminier $^{(10)}$, ${\text { Thierry } \text { Terre }^{(10)} \text {, Martin Visbeck }}^{(11)}$, Johannes Karstensen ${ }^{(11)}$, Gerd Krahmann ${ }^{(11)}$, Alberto Alvarez ${ }^{(12)}$, Michel Rixen ${ }^{(12)}$, Pierre-Marie Poulain ${ }^{(13)}$, Svein Osterhus $^{(14)}$, Joaquin Tintore ${ }^{(15)}$, Simon Ruiz ${ }^{(15)}$, Bartolomeo Garau ${ }^{(15)}$, David Smeed ${ }^{(16)}$, Gwyn Griffiths ${ }^{(16)}$, Lucas Merckelbach $^{(16)}$, Toby Sherwin ${ }^{(17)}$, Claudia Schmid ${ }^{(18)}$, John A. Barth ${ }^{(19)}$, Oscar Schofield ${ }^{(20)}$, Scott Glenn $^{(20)}$, Josh Kohut ${ }^{(20)}$, Mary Jane Perry ${ }^{(21)}$, Charlie Eriksen ${ }^{(2)}$, Uwe Send ${ }^{(23)}$, Russ Davis ${ }^{(23)}$, Daniel Rudnick $^{(23)}$, Jeff Sherman ${ }^{(23)}$, Clayton Jones ${ }^{(24)}$, Douglas Webb ${ }^{(24)}$, Craig Lee ${ }^{(25)}$, Breck Owens $^{(26)}$

(1) LOCEAN-IPSL/CNRS (Laboratoire d'Océanographie et du Climat: Expérimentations et approches numériquesInstitut Pierre Simon Laplace/Centre national de la recherche scientifique), 32 Boulevard Victor, 75739 Paris Cedex 15, France; Université Pierre et Marie Curie, Case 100-Tour 45-55 - 4 Place Jussieu 75252 Paris, France, Email: testor@locean-ipsl.upmc.fr

(2) IMOS (Integrated Marine Observing System), Private Bag 110, Hobart TAS 7001 Australia, Email: Gary.Meyers@imos.org.au

(3) IMOS (Integrated Marine Observing System), Perth Canyon, Perth, Western Australia, Email: chari.pattiaratchi@uwa.edu.au

${ }^{(4)}$ Memorial University of Newfoundland, P.O. Box 4200, St. John's, NL A1C 5S7 Canada, Email: bachmayer@mun.ca

${ }^{(5)}$ UCY/OC (University of. Cyprus - Oceanography Centre), P.O. Box 20537 1678, Nicosia, Cyprus, Email:dhayes@ucy.ac.cy

${ }^{(6)}$ CORIOLIS/IFREMER (French Institute for Exploitation of the Sea/Institut Français de Recherche pour l'Exploitation de la Mer), Centre de Brest, BP 7029280 Plouzané, France, Email: sylvie.pouliquen@ifremer.fr; Loic.Petit.De.La.Villeon@ifremer.fr; Thierry.Carval@ifremer.fr

(7) LEGOS/IRD (Laboratoire d'Études en Géophysique et Océanographie Spatiales/Institut de Recherche pour le Développement), B.P. A5- 98848 - Noumea Cedex - Nouvelle-Calédonie, France Email: alexandre.ganachaud@ird.fr; lionel.gourdeau@noumea.ird.nc

${ }^{(8)}$ LOCEAN-IPSL/ENSTA (Laboratoire d'Océanographie et du Climat Expérimentations et Approches NumériquesInstitut Pierre Simon Laplace/École Nationale Supérieure de Techniques Avancées), 32 Boulevard Victor,

75739 Paris Cedex 15, France; UPMC (Université Pierre \& Marie Curie), Case 100-Tour 45-55 - 4 Place Jussieu 75005 Paris France, Email: Laurent.Mortier@locean-ipsl.upmc.fr

(9) LOV/CNRS (Laboratoire d'Océanographie de Villefranche/Mer/Centre National de la Recherche Scientifique), Chemindu Lazaret, 06230 Villefranche-sur-Mer, France, Email: claustre@obs-vlfr.fr; taillandier@obs-vlfr.fr

${ }^{(10)}$ LPO/IFREMER (Laboratoire de Physique des Océans/French Institute for Exploitation of the Sea/Institut Français de Recherche pour l'Exploitation de la Mer), Centre de Brest, BP 70, 29280 Plouzané, France,

Email: pascale.lherminier@ifremer.fr; Thierry.Terre@ifremer.fr

${ }^{(11)}$ IFM-GEOMAR (Leibniz Institute of Marine Sciences), Düsternbrooker Weg 20, D-24105 Kiel, Germany,

Email: mvisbeck@ifm-geomar.de; jkarstensen@ifm-geomar.de; gkrahmann@ifm-geomar.de;

${ }^{(12)}$ NURC (NATO (North Atlantic Treaty Organization) Undersea Research Centre), Viale San Bartolomeo 400, 19126, La Spezia, Italy,

Email: alvarez@nurc.nato.int; rixen@nurc.nato.int

(13) OGS (Istituto Nazionale Di Oceanografia E Di Geofisica Sperimentale), 42, Frazione Borgo Grotta Gigante, Borgo Grotta Gigante, TS 34010 Italy, Email: ppoulain@inogs.it

${ }^{(14)}$ BCCR (Bjerknes Centre for Climate Research), Allegaten 55, 5007 Bergen, Norway, Email: svein.osterhus@bjerknes.uib.no

${ }^{(15)}$ IMEDEA (Institut Mediterrani d'Estudis Avançats), Esporles, 21, 07190 Esporles, Spain Email: jtintore at socib.es; simon.ruiz@uib.es; tomeu.garau@uib.es

${ }^{(16)}$ NOCS (National Oceanography Centre Southampton), Waterfront Campus, European Way, Southampton SO14 3ZH, United Kingdom,Email:das@noc.ac.uk; gxg@noc.ac.uk; lucas.merckelbach@hzg.de

(17) SAMS (Scottish Association for Marine Science), Oban, Argyll, PA37 1QA United Kingdom Email: toby.sherwin@sams.ac.uk

${ }^{(18)}$ NOAA/AOML/PHOD (National Oceanic and Atmospheric Administration/Atlantic Oceanographic and Meteorological Laboratory/Physical Oceanography Division), 4301 Rickenbacker Causeway,

Miami, Florida, 33149, USA, Email: Claudia.Schmid@noaa.gov 
(19) Oregon State University, 104 COAS Administration Building, Corvallis, OR 97331-5503 USA,

Email: barth@coas.oregonstate.edu

${ }^{(20)}$ Rutgers University, 71 Dudley Road, New Brunswick, NJ 08901, USA, Email: oscar@ imcs.rutgers.edu; glenn@marine.rutgers.edu; kohut@marine.rutgers.edu

${ }^{(21)}$ School of Marine Sciences, University of Maine, 5741 Libby Hall Room 204A Orono, ME 04469-5741, USA,

Email:perrymj@maine.edu

${ }^{(22)}$ School of Oceanography, University of Washington, Box 357940, Seattle, WA 98195-7940, USA,

Email: eriksen@u.washington.edu

${ }^{(23)}$ SIO (Scripps Institution of Oceanography), 9500 Gilman Drive M/C 0214, La Jolla, CA 92093-0214 USA,

Email: usend@ucsd.edu; redavis@ucsd.edu; drudnick@ucsd.edu; jtsherman@ucsd.edu

${ }^{(24)}$ Teledyne Webb Research, Falmouth, 82 Technology Park Dr, East Falmouth, MA 02536-4441, USA,

${ }^{(25)}$ APL-UW (Applied Physics Laboratory-University of Washington), 1013 N.E. 40th St., Seattle, WA 98105, USA,

Email: craig@apl.washington.edu

${ }^{(26)}$ WHOI (Woods Hole Oceanographic Institution), Mailstop 29, Woods Hole, MA 02543, USA,

Email: bowens@whoi.edu

\begin{abstract}
The aim of this community white paper is to make recommendations for a glider component of a global ocean observing system. We first recommend the adoption of an Argo-like data system for gliders. Then, we argue that combining glider deployments with the other components (ships, moorings, floats and satellites) will considerably enhance our capacity for observing the ocean by filling gaps left by the other observing systems. Gliders could be deployed to sample most of the western and eastern boundary circulations and the regional seas (around 20 basins in the world) which are not well covered by the present global ocean observing system and in the vicinity of fixed point time series stations. These plans already involve people scattered around the world in Australia, Canada, Cyprus, France, Germany, Italy, Norway, Spain, UK, and the USA, and will certainly expand to many other countries. A rough estimate of resources required is about $13 \mathrm{M} \$$ /Euro for $\sim 20+$ gliders permanently at sea during five years in the world ocean, based on present scientific infrastructures.
\end{abstract}

\section{INTRODUCTION}

There is a growing awareness of the ocean's role in our life. We know that the ocean play a central role for a number of aspects related to our environment, such as the characteristics and changes of the global/regional climate, the weather, the ecosystems, the living resources and the biodiversity. Knowledge of the ocean is also critical for human activities like science, education, defence, security, rescue, coastal protection, shipping, fisheries, offshore industry, and tourism. The ocean's have not only an enormous storage capacity for various properties through external physical and biogeochemical forcing and internal dynamics, the ability to transport them over far distances. This gives rise to remote effects (in space and time) on currents, water properties, and marine ecosystems, which could be dramatic. Dissolved and particulate matters as well as physical (temperature and salinity) and biogeochemical properties (e.g. pH, oxygen, and nitrate) are transported by the oceanic currents and thus significant shifts or reversals of the circulation have a major impact on marine organisms as well as large ecosystems/communities. Human beings are not immune from these impacts on the ocean environment.

The marine environment is a complex and turbulent system in which strong interactions between physical, chemical, and biological processes takes place. The interaction of these processes occur on scales from a few meters to thousand of kilometres in space and from hours to more than decades in time, which makes it particular challenging to investigate. One basic requirement for a comprehensive analysis of the marine environment is the simultaneous acquisition of the various physical, chemical, and biological parameters. Another requirement is to observe the wide range of spatial end temporal scales. It is clear that only the structured interplay of a variety of observing system components can keep with this challenge.

The international Global Ocean Observing System (GOOS) has been set up to value and organize the different marine observing components into one coherent system. GOOS is a contributor to the Global Earth Observation System of Systems (GEOSS), which exists to monitor the environment and assist stakeholders in taking decisions. The current design of GOOS is not optimized in sampling capabilities (e.g. eastern and western boundary currents are not well sampled) as well as parameter space (e.g. marine ecosystem state variables are only very poorly resolved). It will be shown in this review how gliders can help to further optimize GOOS.

On behalf of the EGO group (Everyone's Gliding Observatories, http://www.ego-network.org/) we will review in this white paper the demonstrated capabilities for observing the ocean of a fairly recent measurement platform, the underwater gliders, that can address these 
gaps. We provide assessments and recommendations, including necessary technical developments, temporal and spatial sampling requirements, core variables, calibration procedures, standards, and a data sharing and release policy. Our paper provides a global point of view and shows how gliders can integrate with other systems, and outlines some plans for an effective implementation at global and basin scale.

\section{IN-SITU OBSERVING SYSTEMS}

In-situ observations of the marine environment have been traditionally carried out by oceanographic ships, moorings, and floats. All these observing platforms can carry out multidisciplinary measurements of the ocean, but not always with the spatio-temporal resolution required. The key point here, is to avoid any aliasing effect leading to erroneous conclusions. During the last 30 years, an increasing number of actions designed to estimate the ocean state or observe how climate change has unfolded in the ocean. Among those, one can distinguish four in-situ observing strategies:

1. Process studies: many oceanic processes require further investigation and require in-situ observations that are able to resolve small and (sub)meso scale $(1-100 \mathrm{~km}$, days/weeks), in relatively large areas (regions/basin) to be carried out. This has been done punctually for a better understanding of the ocean, sometimes with a repeat study (always in winter for instance) in regional seas that are generally important for the global functioning of the ocean (convection sites, eddy-focused studies, vertical mixing at smaller scale, oligotrophy processes, ...).

2. Observing systems for scientific projects: many scientific projects aim to address the oceanic variability at low frequency and have set up observing systems to allow relatively long term observations (years) like repeated transoceanic sections and water samples collection in particular areas (on a week/month to multi-year basis) or mooring arrays (periods of years at a resolution of a few minutes).

3. Observatories: often with a multidisciplinary approach, observatories are set for decades in particular areas (defined by a global vision as much as possible) to focus on particular processes defined by provinces that are characterized by a strong interannual variability.

4. Operational oceanography: the main focus is the real time data coverage and flow of information, as well as archiving, with the major constraint of real time and delayed-mode quality controls. Data centers collect these data and distribute them in a worldwide network including operational forecasting models that in turn can provide an upto-date estimate of the state of the ocean (physical and biogeochemical).

The widest variety of multidisciplinary measurements at high spatial resolution can be obtained from oceanographic research vessels. Unfortunately, logistic and economic aspects often invalidate them as platforms able to carry out continuous and sustained ocean observations. While analyses of hydrographic sections have shown changes between surveys it is often not clear what they mean. This is the case because they cannot be repeated very often, so high frequency variability causes an aliasing and sampling bias problem for hydrographic sections. With less capacity for the measured parameters, ships of opportunity can be used for ocean monitoring but they are constrained to (commercial) timetables and maritime routes. Furthermore, they may need to be manned on each trip and they do not always pass through regions of highest scientific interest.

Unlike oceanographic ships, moorings provide multidisciplinary data with very high temporal resolution over long periods. Nowadays, moorings can operate for more than five years. Satellites and surface buoys and/or submarine cables for data transmission can convert them into sustained ocean observing platforms, allowing near real time data transfer to land bases. Results from moored systems at key locations have documented large variability but it is difficult to extract trends. The spatial resolution is very poor unless a very large (or even unrealistic) number of moorings is considered; consequently, it is often impossible to separate spatial and temporal variability.

The international Argo program has been very successful in providing the first intensive data coverage of temperature and salinity in the upper 1000 to $2000 \mathrm{~m}$ of the world ocean. This global array of profiling floats has been recently implemented and is a network capable of monitoring the global ocean in a full operational sense. A large number of floats makes it possible to monitor the ocean "randomly" and "on average" in a global manner, each float providing data every 10 days or so. The present array configuration of $\sim 3000$ floats gives a horizontal resolution (average distance between floats) of around $300 \mathrm{~km}$, in case the floats would be distributed evenly, and which is adequate to derive mean quantities as the average heat content or temperature on time scales of month. This is a rather coarse spatial and temporal resolution, which is difficult to increase. The number of floats required varies roughly quadratically with the average horizontal resolution of the system and in addition, floats drift out of divergent regions and into convergence regions according to the currents, which leads to uncontrolled gaps in the data coverage. Floats have to be reseeded 
frequently in the regions of strong divergence. Furthermore, the original design of the Argo array excluded marginal seas due to technical difficulties. The primary reason for this is that the life expectancy of a float is quite short in these regions, mainly due to grounding and stranding. This is critical not only when regional and/or coastal issues are to be addressed but also affects the global scale. Currently, the Argo program concentrates on physical measurements only but advances in biogeochemical sensors [1] may soon open the array for multidisciplinary research.

Fundamental advances in understanding the physical, chemical and biological functioning of the oceans have been achieved based on all different types of in-situ observations. Further progress was the combination of in-situ data with satellite remotely sensed data. Satellites provide data in exceptional high spatial resolution and on a global scale. However, they suffer from not being able to resolve the vertical structure of the ocean. In addition, technical problems exist for example in sampling ocean boundary or often signals cannot be interpreted due to measurement problems as occur from clouds or rain signatures.

It is clear that the current state of the in-situ interior ocean observing system has a much lower horizontal resolution than the surface observations provided by satellites. Fortunately, the interior ocean does not change as quickly as the surface ocean and as such an as-high resolution network of in-situ observations is not required. However, what is required is sampling "critical regions" to improve seasonal forecasting [2], regional climate, or for applications that require better estimates of the currents such as security or shipping. What is also required is sampling a variety of different physical, chemical, and biological parameters to estimate the state of the marine ecosystem (CO2 pump, ecosystem management, fisheries). For these reasons and with the help of technological developments, new ocean observing platforms able to be steered remotely, and able to carry out continuously ocean measurements at high spatial and temporal resolution, have been developed. Gliders come from the idea [3] that a network of small, intelligent, and cheap observing platforms can fill the gaps left by the other observing systems. That idea was further developed at OceanObs in 1999 [4], when the technology was still immature, and this paper provides an update for what is now an adolescent technology, poised to make a substantial contribution to global ocean observing.

\section{GLIDER CAPABILITIES}

Gliders have enhanced capabilities, when compared with profiling floats, by providing some level of manoeuvrability and hence position control. The gliders perform saw-tooth trajectories from the surface to depths of $1000-1500 \mathrm{~m}$, along reprogrammable routes (using two-way communication via satellite). They achieve forward speeds of up to $40 \mathrm{~km} /$ day thanks to wings and rudders, and can be operated for a few months before they have to be recovered [5] and [6]. Gliders can record physical and biogeochemical parameters during the dives. Even passive and active acoustic instruments have successfully been used. At each surfacing, they connect to a computer on land via the bidirectional iridium satellite phone system in order to send the data they collected and receive new commands, if necessary (at a rate of about 30-60Kbytes in 5 minutes every $\sim-5$ hours). Gliders are postulated to be less susceptible to damage from fish trawling than moorings and hourly/daily communication by satellite means that if a vehicle is lost or damaged the loss of data can be minimized. Replacing a glider is relatively easy and cheap compared to other operations at sea.

First conceived in 1986 [7], the concept of use was developed in 1989 [3], with the first prototype flight tests carried out in 1991 [8] and after a 'teenager' period starting around 2002, gliders are now being incorporated into the operational technology portfolios of many research institutions and agencies. It has been demonstrated that gliders are able to carry out high resolution measurements of not only physical (temperature and salinity as well as average velocities over a dive) but also biogeochemical parameters such as dissolved oxygen and fluorescence/optical backscattering at various angles and wavelengths (giving estimates of the Chla, Colored Dissolved Organic Matter, and Phycoerythrin concentrations, as well as the water turbidity and particle sizes). An example of data collected by a glider is shown in Figure 1 , but there are many other experiments reported in the literature [10], [11], [12], [13], [14], [15], [16] , [17], [18] and [19] demonstrating that gliders can cover transects of hundreds of $\mathrm{km}$, gathering physical and a biogeochemical data, on a long term basis (several months per deployment). Gliders can even contribute to studies on the behaviour of whales through acoustic 
sensors [20]. Gliders have now a substantial track record, and the utility of autonomous underwater gliders for collecting oceanic profiles has been convincingly demonstrated. This includes (a) demonstrating the ability to fly gliders in coordinated fleets, (b) demonstrating the ability to fly gliders into severe

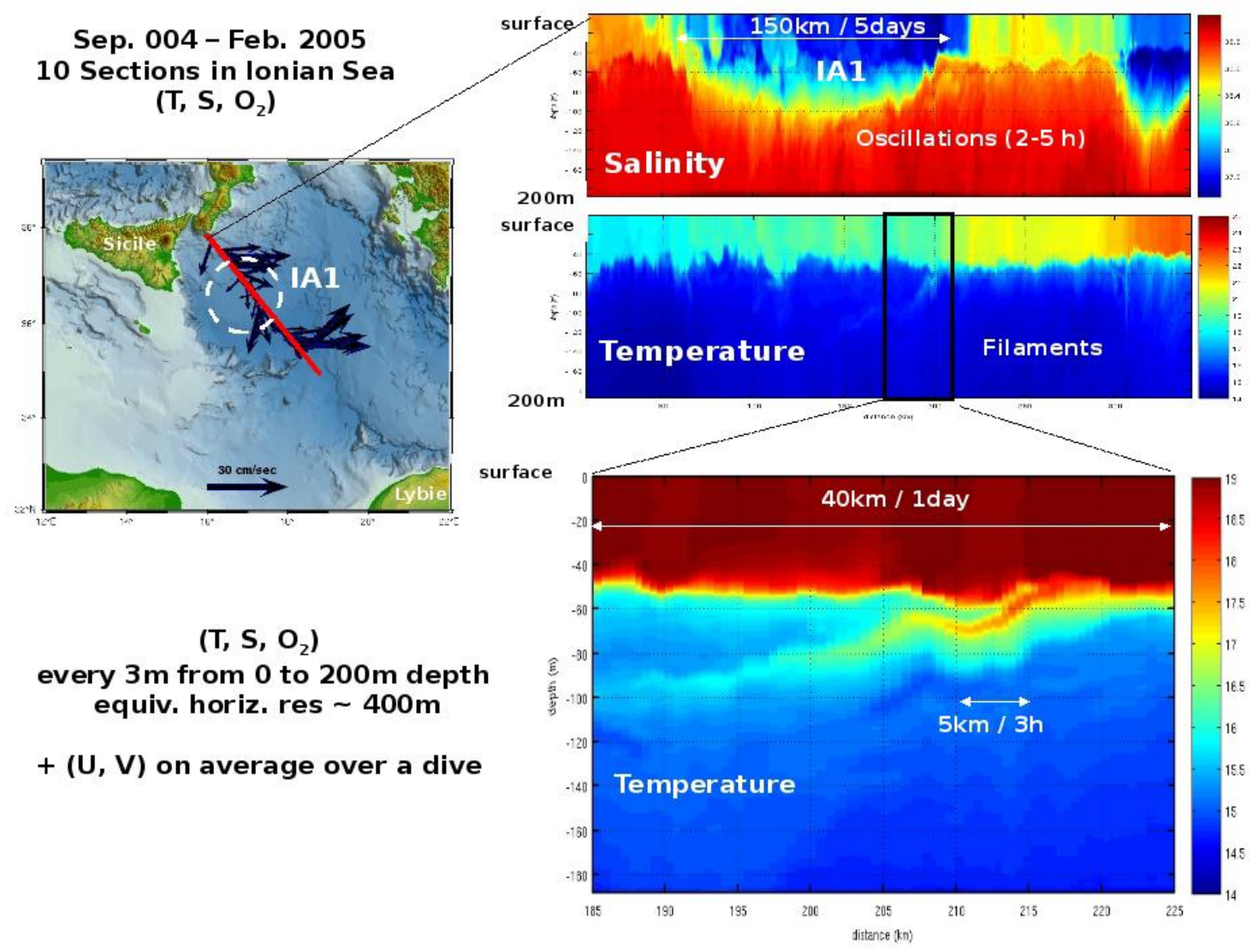

Figure 1: transect carried out in the central Mediterranean Sea with a shallow glider illustrating how fine scale processes can be resolved with gliders. A sharp front of salinity (right panel) is associated with strong currents (left panel) and important vertical motions are demonstrated by the sharp tongue of descending warm waters from the mixed layer (right lower panel). [9]

storms/hurricanes and strong currents and (c) demonstrating that gliders can fly long-duration sections. Each of these demonstration projects was completed over the last 10 years.

Figure 2 gives an example of repeat sections, operated over years, in the eastern Pacific [11]. Similar long sections exist along the coasts of the USA in the Pacific, and in the Atlantic [13], [17 and [21] and demonstrated the capacity of gliders to carry out, over many years, measurements of the local vertical structure of the ocean over $0-200 \mathrm{~m}$ or $0-1000 \mathrm{~m}$ from the near-shore environment (10-100m depth) to the open sea (hundreds of $\mathrm{km}$ offshore). Other important orders of magnitude about gliders are (1) the longest glider section ever done with one set of batteries is $6000 \mathrm{~km}$ long [12] and (2) crossing very high currents, such as the Gulf Stream, is possible [22]. At the time of writing two gliders are on trans-Atlantic transects (the shallow electric Slocum glider RU27 from Rutgers University, and a Slocum thermal glider from Webb Research ${ }^{1}$ ).

Gliders are relatively slow and that obviously raises some issues about whether the observations can be treated as synoptic: hence the question, how representative of the ocean state are the collected profiles? This problem is a major one, but it can be solved by increasing the number of instruments at sea

\footnotetext{
${ }^{1}$ http://rucool.marine.rutgers.edu/atlantic/status updates. $\underline{\mathrm{html}}$
} 

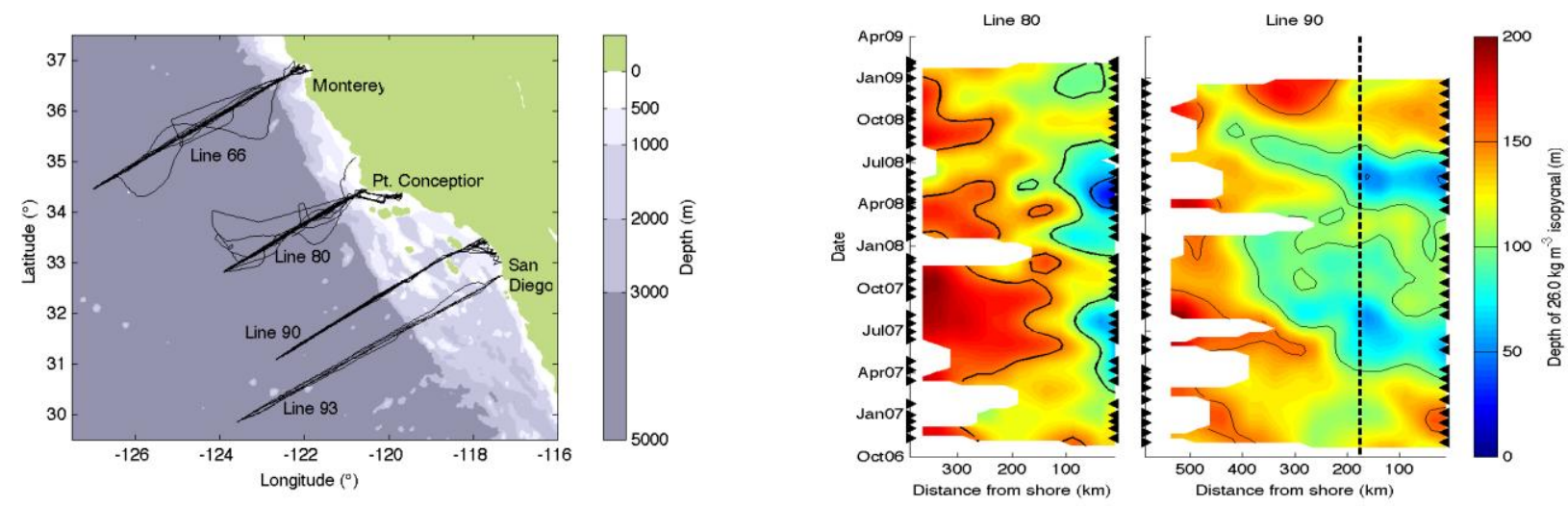

Figure 2: (left panel) glider transects [0-1000m depth] between Sept. 2005 and Apr. 2009 are shown as solid lines. (right panel) Hovmuller diagram of the depth of the $26 \mathrm{~kg} / \mathrm{m} 3$ isopycnal on lines 80 and 90 . Note the tendency for westward propagation along line 90, especially west of the Santa Rosa Ridge (marked with a dashed line). Westward propagation is not readily apparent along line 80.

(point measurements) at the same time, which is the float/glider philosophy.

Figure 3 shows an example of a fleet of gliders on the shelf; these have altimeters on board to avoid grounding. Deep gliders can operate as long as the water depth exceeds more than $10-100 \mathrm{~m}$. If the water is too shallow, the manoeuvrability of gliders decreases due to the time spent at surface compared to the time spent at depth. This limit depends on the glider mode. A buoyancy pump designed to operate at less than $200 \mathrm{~m}$ is faster (and allows operations in shallow coastal waters $\sim 10 \mathrm{~m}$ deep) than a pump used for $1000 \mathrm{~m}$ dives and requiring operations in deeper waters $(>50 \mathrm{~m})$ in order to overcome the currents averaged over the dives. Other experiments have demonstrated that relatively small fleets (5-15 gliders) can be deployed for extended periods in the same area (at coastal and regional scales) in the Atlantic, in the Pacific, and in the Mediterranean [13], [23], [24] and [25].

Considering the oceanic variability measured so far, a relatively small number of gliders already helps characterize the deep variability. Most of the interior oceanic waves have scales on the order of the radius of deformation $\left(2 * \mathrm{pi}^{*} 10-100 \mathrm{~km}\right)$ and propagate at less than $10 \mathrm{~cm} / \mathrm{s}$, which means that the ocean is changing only slowly. Having a speed of $\sim 30-40 \mathrm{~km} /$ day horizontally, gliders are perfectly suited to sample oceanic features and eddies that propagate slower; Doppler effects are not problematic since the speed of the platform is known. With the exception of western boundary currents, oceanic currents generally do not exceed the gliders' speed. Even in such strong currents, there is still some manoeuvrability, because the glider route, or list of waypoints, is reprogrammable. One can fly gliders perpendicular to the measured currents to 'escape' the area characterized by strong currents, or one can keep heading constant (the targeted waypoint is at an 'infinite' distance) during the next cycles to 'ignore' oscillatory circulations. This can be very useful if there are strong tidal currents. Gliders can use the last average current measured, or even predict tidal currents internally with a Kalman filter, to improve their deadreckoning navigation, and adjust their heading accordingly during the next dive [5].

Since gliders are active (remotely steerable), they can cover a wide range of missions and complex sampling strategies. Numerous possibilities have been demonstrated, for example: virtual mooring (Eulerian sampling by collecting profiles at a tightly controlled location) or quasi-Lagrangian (profiling following the currents, i.e. behave like a profiling float until manoeuvrability is necessary).

There are many possible configurations especially when one consider several gliders working together. Gliders bring new capacity to many types of studies persistence is key when considering glider sampling. They could be commanded individually to stay in a region for a while (around a mooring array for instance [15] and [26], or to follow an oceanic feature (a front or an eddy, [17], [18] and [27] or even living beings like penguins. Glider tracks can be subject to constraints, for example optimizing a mapping skill [28] or keeping the same distance between all the gliders in a fleet, or flying gliders almost perpendicular to the oceanic average currents they measure (to get better gradients and overcome strong currents), or towards relative extrema/singularities in the measured fields (such as latitude and longitude of minima, maxima, or saddle points, at particular depths). Robust algorithms to perform such piloting have already been tested at sea [29 and 30] and tools to adapt the waypoints list using the environment sensed by satellite have been developed to optimize the glider speed [31 and 32]. 
It is now clear that gliders can be combined into networks of small and intelligent platforms that are able to fill the gaps left by other observing platforms by delivering high resolution and near real-time in situ observations of physical and biogeochemical properties along their paths. The utilization of glider technology will allow us to reach a level of coverage and accuracy never reached before in ocean monitoring for such parameters. Glider deployments in concert with other observing networks (satellites, ships, floats, moorings) can significantly enhance the ocean observing capabilities for the upper $1-1.5 \mathrm{~km}$ of the ocean [33]. The goal could even be to map the characteristics at deep levels with a (sub)mesoscale resolution (certainly for a limited number of areas in the world) with as much impact on the quality of the estimate of the ocean state as satellite data. Locating the depths with the highest gradients of various parameters (e.g. the thermocline, pycnocline, nutricline, subsurface maxima and minima, the mixed layer depth, as well as various isopycnals, isotherms, isohalines that separate different water masses) are prerequisites to get a good ocean state estimate. Many additional variables come into play for ocean biogeochemistry. We need to know the subsurface chlorophyll distribution (maximum, depth and horizontal extent), the characteristics of the oxygen minimum zones, as well as the turbidity of the water. These are important aspects to consider if one wants to satisfy the needs for the societal applications that are not covered by the existing, predominantly physical, observing system.

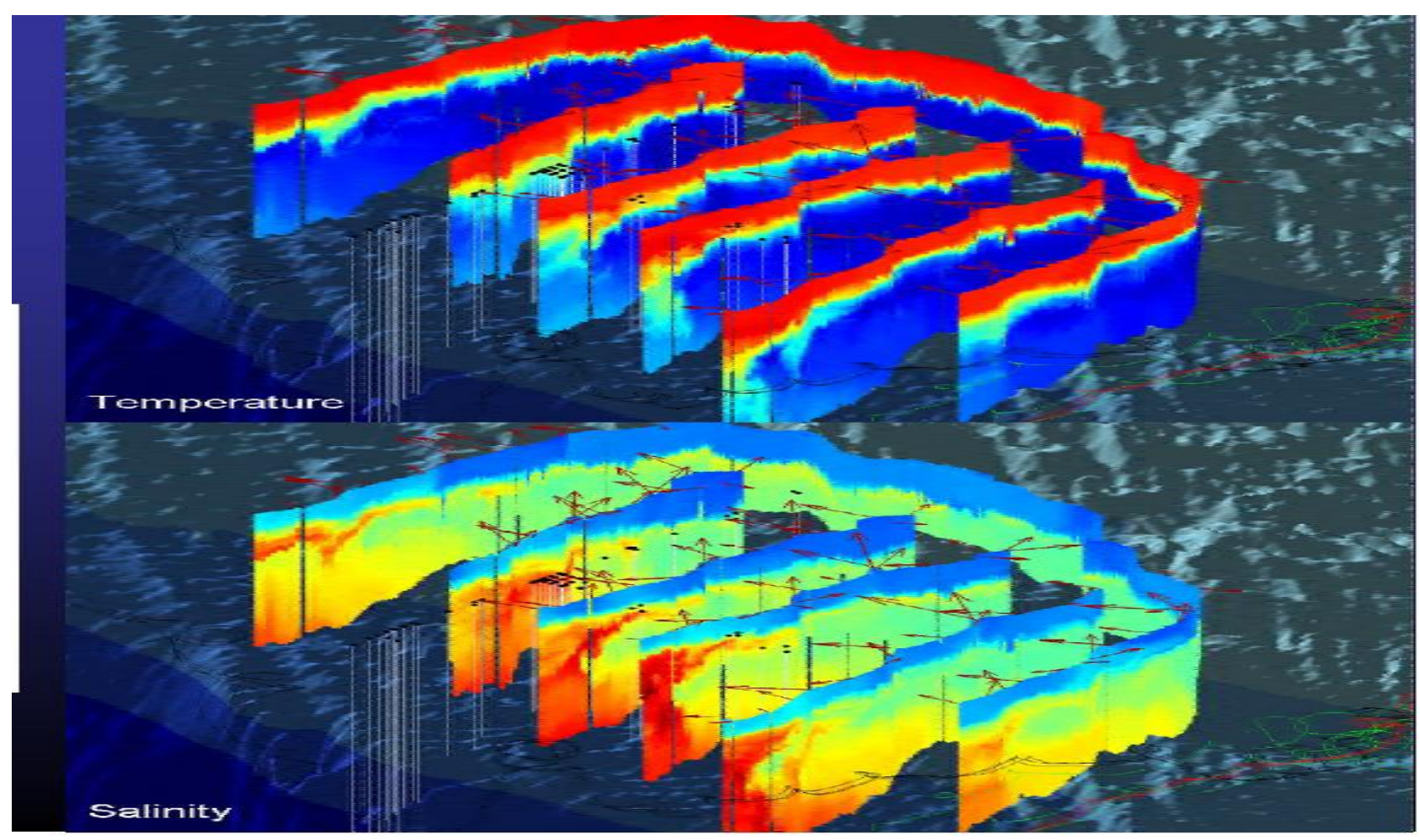

Figure 3: 6 gliders deployed at the same time in 2006, enabling a 3D view of temperature and salinity on the shelf of New Jersey (Courtesy of Rutgers University) 
Gliders open wide perspectives but there are some disadvantages and logistical constraints with the use of gliders that one must consider. Currently, the endurance of 3-7 months limits the dreams. The maximum endurance ever reached up to now is 8 months in the water [12], and 10 months of endurance is likely. This of course strongly depends on the kind of glider, its speed, and scientific payload. Even if technological developments could help to increase that endurance, there will always be problems related to corrosion, biofouling, sharks, collisions with ships, etc. We do not foresee an increase of glider endurance by an order of magnitude in the coming decade. The constraints are not only endurance but also local support expertise and logistics. Gliders are complex systems that can be in operation for years but need to be serviced between deployments by highly proficient marine engineers and technicians. Periodic maintenances include exchange of the batteries, calibration of sensors, updating the hardand soft-ware. This task is technologically demanding and requires expert people and dedicated devices (e.g. pressure and calibration tanks) that are already available, but only in a few places.

\section{OBSERVING AND MODELLING}

Major impact will come from the increased accuracy of oceanic models (physical and biogeochemical) synthesizing all observations. Meteorology gives a good example but the deformation radius in the ocean is much smaller and time scales much longer and so, a specific approach has to be developed. A reference case is now a number of operational systems that run, generally on a daily to weekly basis, to analyse or forecast the state of the ocean. Every day or so, they can assimilate profiles from floats, CTDs (ConductivityTemperature-Depth), XBTs (Expendable Bathythermograph), gliders, moorings and derive nowcasts and forecasts of the physical state of the ocean at a horizontal resolution of about $1-50 \mathrm{~km}$, on regional or global scales, with a time-step of minutes, hours or days. The products are strongly dependant on (1) all profiles acquired until now (climatologies/initial conditions), and (2) a number of 'weighted' contemporary vertical profiles selected with a criteria based on the model capabilities, in order to be assimilated. Models for biogeochemical cycles using the computed physical environment as a variable can already provide an estimate of the marine ecosystem, and the assimilation of biogeochemical data is work in progress towards a "green" ocean forecasting system [34].

\subsection{From global to regional scale and reciprocally}

The coverage (with associated spatial and temporal resolutions) of the in situ observing system is a limiting factor, and up to now most of the in situ data assimilated in ocean models are T/S (Temperature/Salinity) profiles from the Argo project, which has provided a real jump in the coverage of the ocean with in situ observations. Together with satellite information, the Argo profiles can characterize only the relatively low-frequency and large scale processes. The finer scale processes (also present in the profile data) are attributed either to "noise" that the model cannot represent, or to representativeness errors. A resolution of $300 \mathrm{~km}$ and 10-days is sufficient for a number of purposes related to the global oceanic heat and salt content and variability, as well as large-scale transports, at seasonal to decadal scales (the objectives of Argo). However, we really need better data coverage at relatively small (even meso- and submeso-) scale to constrain models. This is particularly critical for areas at the regional/coastal scale that are important for the physical and biogeochemical functioning of the ocean at global scale [35] and [36].

Divergence zones and the boundary currents near the continental slope or steep topographic features are problematic. Floats never stay long in such areas, often characterized by energetic currents, or run aground if they drift too close to the coast. This is a problem, since these regions have a significant impact on the global state of the ocean. For instance, Mariano et al. [37] found that a modelled Gulf Stream could be strongly altered by introducing small and fluctuating boundary conditions. This would mean that a better characterization of the flow near the boundaries could correct a model on the large scale, through data assimilation, and increase its capacity to represent/predict the ocean.

For such reasons, regional/coastal observing and forecasting systems have been developed (e.g. ECOFS European Coastal Observing and Forecasting Systems). Nowadays, a solution could come from coastal/regional models nested into more global ones and 'fed' by convenient real-time data. There is the potential for a two-way feedback between the two nested models, the coarse-resolution (global) model providing boundary conditions for the high-resolution regional model, and the regional model providing feedbacks to the coarseresolution model. However, not only the good, wanted, information but also errors propagate through the boundaries and there is a strong need for data that can constrain both global and regional models for all possible applications.

\subsection{Glider data for operational oceanography}

At the moment, the assimilation of glider data is already operational for $\mathrm{T}-\mathrm{S}$, in regional (Mediterranean/MFS (Mediterranean Forecasting System; Pacific/NCOM (NRL (Naval Research Laboratory) Coastal Ocean Model) or even global (North Atlantic/MERCATOR) models. The gliders provide profiles to Data Centres in 
real-time. The glider profiles are treated like profiles from profiling floats or ships. An important point is that the number of the glider profiles (among those available) used in the data assimilation process is dependant on the model's capability (mainly horizontal resolution) in representing oceanic processes. The example of the assimilation of data from the glider spray004 (deployed in the North Eastern Atlantic) by MERCATOR [26] illustrates the glider data usage at global scale. In the framework of AOSN (Autonomous Ocean Sampling Network) and MFSTEP (regional/coastal scale models) relatively more data from the deployed gliders could be assimilated [38 and 39], because these models are able to resolve finer scales.

The basic numbers for one single glider repeat-section of about $300 \mathrm{~km}$ length (from a coast towards the basin interior, for instance, for easy maintenance), are around 50 (250) profiles down to $1000 \mathrm{~m}(200 \mathrm{~m})$ depth carried out along this section over 10 days. This section can be repeated multiple times. Global and regional operational models would have different usage of these glider profiles. The global model would likely use very few of the collected profiles, the ones that are the most convenient for the model. Because 10 days is about $\sim 300 \mathrm{~km}$ of glider travel, which is also the 'Argo' scale, a global model would likely, use only 2 profiles, the ones that are the furthest from each other in time-space. In contrast, the regional model will use most of them because it is able to resolve much finer-scale processes. Here, the key aspect is the focus on the glider data that is possible with the model, which assimilates those data.

The repetitiveness of measurements over sections of $300 \mathrm{~km}$ length (and carried out in $\sim 10$-days) seems to really help regional models to adjust their state [39] eliminating phase shifts between the ocean estimate and the real circulation and resulting in a better consistency with patterns in some of the external (atmospheric) forcing. The assimilation of average velocities measured by gliders is envisioned in the same way, as it can be done now for the profiling floats trajectories [40]. A much better accuracy for the ocean state estimates could be expected as current data provides the model with some information on the horizontal gradients and curvatures along the glider and float trajectories because of the geostrophic balance and that combines well with the information from the vertical profiles.

\section{IMPLEMENTATION FOR GLOBAL OR BASIN SCALE}

\subsection{Data flow}

The first and essential step towards a glider component of a global/basin scale observing system is to ensure the collected data by gliders are disseminated to the oceanographic community and in particular to the operational models via data centres including Quality Control procedures.

A glider profile consists in the data collected between the surface and maximum depth reached by the glider during descent and/or ascent. The glide angle (typically $17-26^{\circ}$ ) being much steeper than oceanic slopes, a glider profile can be considered as vertical and the accuracy of GPS fixes during surfacing allows one to locate glider profiles with an accuracy of less a kilometre. The accuracy specifications for $\mathrm{T}-\mathrm{S}$ measurements are the same as for profiling floats. Nowadays, glider profiles transmitted in real-time to the Coriolis Data Center are considered like any other profile. The quality control for glider data is the same as for CTD/XBT/Argo and is mainly based on:

- flag T and S outliers, based on historical data and density inversions;

- visual inspection.

Comparisons with classical ship profiles at the deployment and/or recovery help increase the accuracy. Thermal lag correction is an important issue in autonomous vehicles and a new technique has been developed for gliders [41], which considerably reduces the errors in the estimation of salinity from CTD sensors.

New quality control methodologies need to be applied to the other glider data. The quality control and calibration procedures for other parameters (oxygen, fluorescence, backscatter, turbidity, etc.) are now being defined, as there is a need for standards and procedures for data other than temperature and salinity, and for platforms other than gliders. This problem is also raised by some profiling floats, as they already measure oxygen. Developing quality control procedures for such biogeochemical parameters is envisioned for the future [1], for both gliders and profiling floats.

Enhancing the data usage of glider data in operational and research application will be possible if an easy access to glider data is organized at the international level. Based on the Argo experience for profilers, and the European EGO initiative for gliders, a global portal to glider data, processed at national or institutional level, quality controlled using homogeneous procedures and freely accessible from a single point in a unique format with a good set of meta data would really move gliders from a research platform to an important component of the global ocean observing system.

Meta data, such as the vehicle name, unique identifier (maybe WMO ID (World Meteorological Organization International Identifier) deployment name, principal investigator, project, sensors on board, waypoints/heading, angle of ascent/descent, target 
maximum depth, target minimum depth, target altitude above ocean bottom, time at surface, current correction, or underwater estimated positions are also essential information for a database at global scale.

We all agree to have the same data policy for global use similar to the Argo float data management policy. Through this approach, any glider deployed with a given observing strategy even if in a regional context, can contribute to ocean observations at the global scale. This could also help with the legal issues raised by gliders [42], which are similar to the ones raised by the operation of profiling floats. This is starting to be discussed in the framework of UNCLOS (United Nations Convention on Law of the Sea).

\subsection{Logistical constraints}

The goal is to deploy 'ready-to-go' gliders but operational deployments without external support (manufacturer or another expert glider team) are not yet really feasible. We anticipate that this situation will change rapidly (within the next few years) and also that more experienced people with gliders will be scattered around the world. We would recommend that one of the main objectives for an implementation plan would be to facilitate the establishment of worldwide technical and organisational capabilities to deploy, control, and maintain gliders in operational conditions, with capacity-building actions like exchange programs for scientists, engineers, and technicians (including students). Here, a key point is training of personal and the coordination of standards between glider centres.

Sustained deployments at global scale could be done even from small (rubber) boats near the shore when there is an access to a local support base. Elsewhere, phasing in glider experiments with research vessels is necessary. Those that are not likely to have the ship back in the same region every 3-7 months or so should be careful to keep their gliders relatively close to a harbour where small boats could be chartered for either deployment or recovery. However, the range of gliders is $2000-5000 \mathrm{~km}(2300 \mathrm{~km}$ in 3 months at the average horizontal speed of $\sim 25 \mathrm{~cm} / \mathrm{s}$ including the platform horizontal speed relative to water $\sim 30-40 \mathrm{~cm} / \mathrm{s}$ and average currents over the dives). This already allows gliders to cover almost the whole ocean when deployed from the coast. For instance, there is about $800 \mathrm{~km}$ between the north and south in the Mediterranean, 1300 $\mathrm{km}$ between Newfoundland and Greenland, $1500 \mathrm{~km}$ between Norway and Greenland, $2000 \mathrm{~km}$ between Greenland and UK, $1000 \mathrm{~km}$ between USA and Bermuda, $2500 \mathrm{~km}$ between Europe and Canary Islands or Azores, $2800 \mathrm{~km}$ between Africa and South America, the Drake passage is $1000 \mathrm{~km}$ wide, etc.

\subsection{Technological developments}

Currently, there is perhaps about a $10 \%$ probability of loss of gliders on each mission of a few months. Currently it is feasible that almost all gliders could be maintained at relatively low cost. The oldest known glider is now $\sim 5$ years old and still running. The technology is generally robust and applications are broadening with developing technologies. Figure $4 \mathrm{a}$ shows an example of gliders being used in combination with mooring to perform underwater positioning [45]. The Davis Strait program has conducted multi-month missions successfully, complete with acoustic navigation, going back and forth under sea ice in the winter. New technologies can be: a) data acoustic telemetry considered in [46] b) combining gliders with facilities connected to sea-floor cables, resulting in undersea docking sites c) more efficient batteries (or even miniature fuel cells) or d) glider hardware (such as the thermal buoyancy engine harvesting energy from the ocean temperature gradients), can allow even more networking, more sensors to be included, and/or an increase the glider speed and range. In addition, the development of composite hulls (with a compressibility close to that of seawater) has been done for $1000 \mathrm{~m}$ gliders and is work in progress for deeper gliders. Gliders able to dive to $6000 \mathrm{~m}$ depth are being developed [47] and open wide perspectives since $98 \%$ of the ocean is less than $6000 \mathrm{~m}$ deep. A first version has operated to over $2700 \mathrm{~m}$ depth. Its pressure hull recently was tested successfully to $\sim 6500 \mathrm{dbar}$ pressure. Projections of mission endurance and range for this vehicle suggest missions 18 months long covering $10,000 \mathrm{~km}$ through the water while diving continuously to $6000 \mathrm{~m}$. The concept of expendable gliders should also be considered (one-use only, avoid recovery), since at some point in their lives they are likely to be lost. This loss is because of the inherent risks in the marine environment (e.g. corrosion, biofouling, maritime traffic, animals) and also from ageing and fatigue.

In terms of scientific payload, a glider will not be able to carry all possible sensors on board. Its payload capacity is limited (size, weight, power and energy consumption) but using several gliders with different payloads could partially overcome this problem. The present development of various smaller, and smarter, sensors for gliders is very promising. In addition to the already accessible parameters, direct current measurements (by a small ADCP (Acoustic Doppler Current Profilers)) and dissolved nitrate [48] which are not yet practical with gliders, will be available soon.

\subsection{Navigation}

At the moment, one single glider requires a group of a few people to steer it day and night, and the same group can certainly perform well for a small fleet. However, 
a)

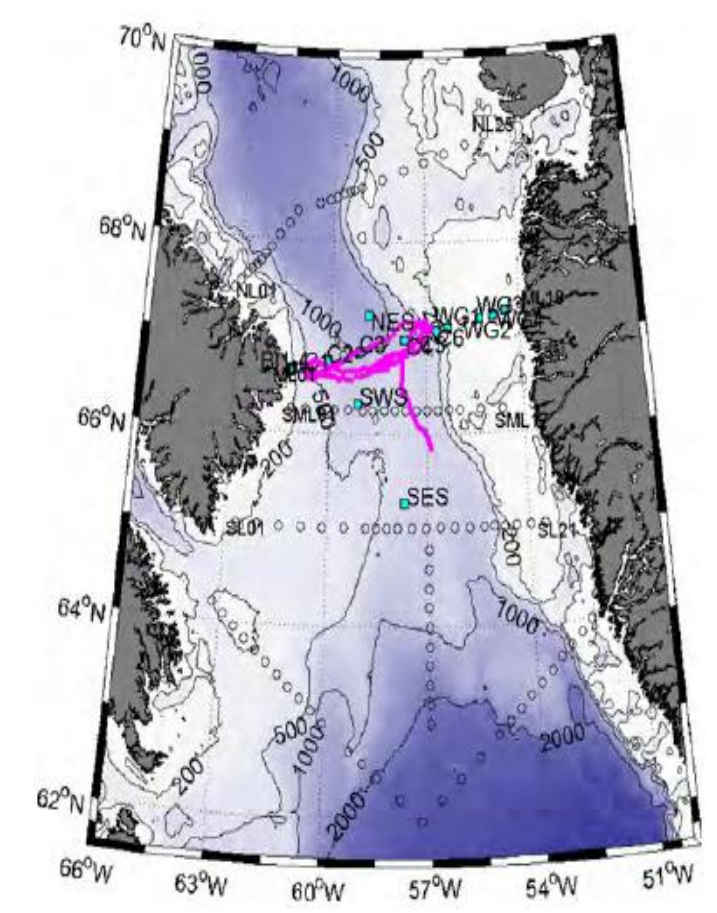

b)

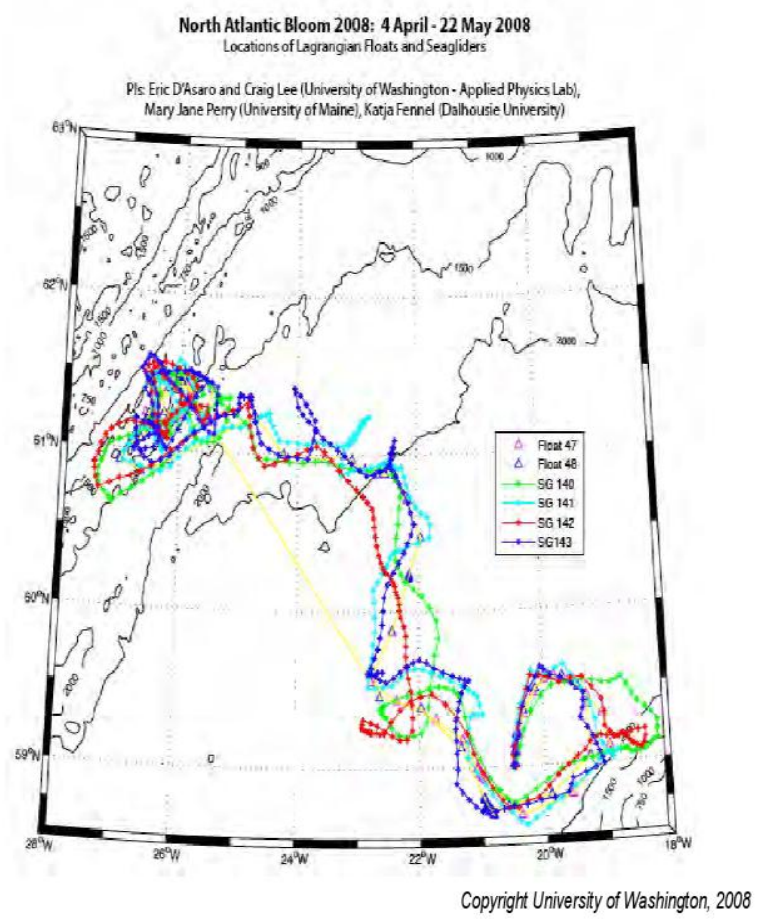

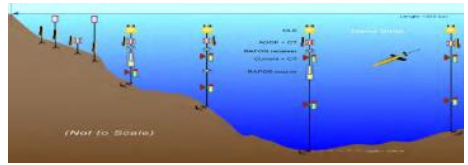

Figure 4: a) Example of the Davis Strait glider experiment [43]. b) Example of floats followed by 4 Seagliders [44]. These heavily instrumented Lagrangian Mixed Layer float were deployed to define a drifting reference frame and the gliders were use to characterize the $3 D$ evolution around this 'water parcel'. An intensive process cruise provided critical data for this study. Trajectories of floats (triangles) and gliders (red, blue, green, cyan).

there is a limit, which is the number of devices a human being can control at the same time. At the moment, about 20 gliders are flying at any one time in the world's ocean, with missions managed by $\sim 4-6$ different teams at the same time and sampling about 4-8 different areas. No doubt, this global glider capacity will increase rapidly in the coming years.

The development of software and Internet tools to steer swarms of gliders is one major innovation that will help to generalize the use of gliders. Another crucial aspect is to increase the number of "glider-ports" where gliders could be (1) deployed/recovered, (2) partly or fully refurbished, and/or (3) piloted. These developments will have to be based on networking, on efficient manmachine interfaces, tools from artificial intelligence, and drawing upon at-sea experience in order to be useful.

Gliders are autonomous but relatively simple robots. There could certainly be more intelligence in gliders. It is limited by the platform itself because gliders need small and low-power hardware. On the other hand, this can be insured by a supervisor on land and transferred in an asynchronous way to the gliders over the satellite communication link. The supervisor is generally a number of people, organized in shifts, who make decisions regarding waypoints and action items.

Because human capacities are limited, it is very attractive to design a machine that helps to control fleets of gliders. Adaptive sampling opens new and wide perspectives but this can only be achieved with better communication and information systems, allowing better navigation. We would need automated systems that are able to easily generate a (large) number of individual commands and appropriate reactions for a network of gliders of various types, when given a specific sampling objective. Such a system also needs to interpret individual gliders performance indicators (for example the rate of discharge of batteries and 
malfunctions in hardware). Providing timely information to the glider pilot about weather forecasts, ocean model outputs (currents and other parameters), satellites images, positions and profiles of other moving platforms (like the positions of floats or gliders presented in Fig. 4b, but also ships) is necessary to fly gliders in well defined contexts and consequently, more efficiently. Many problems cannot be approached solely with autonomous platforms but several groups have demonstrated that gliders can be piloted with high manoeuvrability and quick responses, if relevant information is available.

Because in-situ observing systems composed of fixed or moving platforms are inherently dependent on the positions of the platforms, the main problem is to find the optimal topology for gliders networks (the 'elastic' component) in relation to the gaps in pre-existing networks (in-situ and satellites). This depends, obviously, on the objectives of the networks in terms of spatial and temporal resolution, the nature and variability of the parameters to be monitored as well as on the estimate of the ocean state used for the decision. An evolution of a glider fleet in terms of data coverage could even be dictated by the model needs in real-time, through error maps. Documenting the impact of such observing systems (designed with a specific objective) beforehand is possible, generally with scale considerations or if too complex, via simulations [49] and Observing System Simulation Experiments (OSSEs) as it is done for other components of the observing system in the framework of GOOS [50]. Here, physical parameters (temperature, salinity, currents), as well as all the biological proxies collected through the various optical sensors that can be carried on gliders, must be considered.

\section{GLIDING IN THE COMING DECADE}

Gliders are able to monitor key regions in the world where one needs a collection of data that is more systematic or provides a higher resolution than presently available. Gliders can collect biogeochemical data as effectively as the profiling floats equipped with biooptical sensors [1] and [51] that are being deployed for a "green" global observing system. As one can now focus on the water column, intercomparison with satellite optical products looks very promising for the assessment of whole ecosystems evolving in a changing environment. At the moment, a number of projects with gliders emerge with objectives related to these issues. Using gliders in concert with other platforms can really provide much more complete spatial and temporal coverage for ocean observation with benefits to scientists and end-users including policy makers.

\subsection{Assessing the variability around long-term time series sites}

We recommend gliders be used between moorings in order to enhance the capabilities of the two observing systems. The idea is to complement ocean observation sites [46] in order to better take the pulse of the ocean. The objective is to evaluate the scales of correlation of these fixed-point measurements and to assess the significance of the signals at these locations with respect to a whole area. In addition, it is planned to use gliders in the mix of technologies deployed for the near real time acquisition of deep long-term time series. Gliders could be used as messengers between deep instruments and the surface, acoustic telemetry allowing a near real time data collection that could hardly be possible otherwise (as one would need a surface buoy which is difficult to maintain or one would need a connection to sea-floor cables which are very expensive to install). A number of sites could be enhanced with gliders operating routinely. Deployments and recoveries of gliders around the moorings are possible during the time of the cruises needed for routine maintenance of the moorings but they are usually maintained during cruises on an annual basis and that hardly fits with the glider endurance. An alternative is to consider deployments an/or recoveries from the shore which is possible for mooring sites situated at less than $\sim 1000 \mathrm{~km}$ from a coast.

\subsection{Plans for global and sustained glider observations at regional scale}

At global scale, glider profiles would be used in an analogous way to Argo profiles but always maintained in 'regions'. It has been stressed that gliders could complement the present array, by steering gliders where floats, animals, and ships do not go (the coastal and regional seas are badly covered by the present array), or even use them for cross-calibration (meeting points).

Demonstrations with gliders have been made in coastal environments, in extreme weather conditions and in various places, even in the worst ones for marine equipment such as deep water formation sites and high latitudes (Labrador Sea, Mediterranean Sea, Greenland Sea, Arctic and Southern Oceans), but also in the West/East North-Atlantic (New Jersey, Florida, Irminger Sea, Porcupine Sea Bight, Gascogne, Faroe Bank Overflows, Iceland Basin, Davis Strait Norwegian Sea, the North Sea, the Baltic Sea), and in the West/East Pacific. (Kuroshio, Gulf of Alaska, Philippines, Hawaii, Washington, Oregon, California, Peru, Chile). The first results are outstanding, and there is a general agreement that sustained glider observations (via repeat-sections) at such regional scale would be appropriate for monitoring such regions, because gliders are able to scan a wide range of oceanic features. 


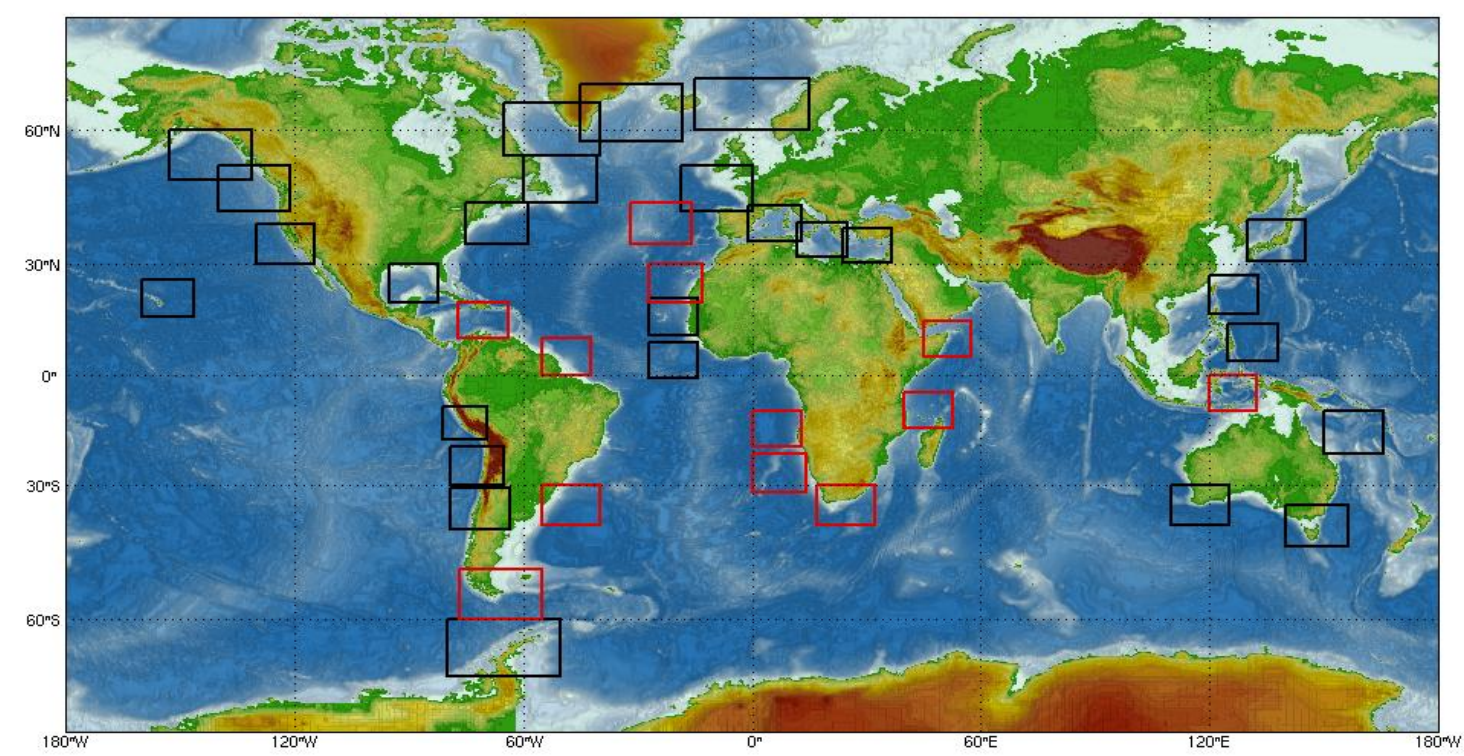

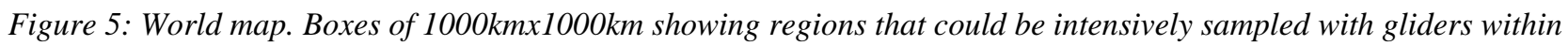
the next 10 years. Gliders have been already deployed at least once in black boxes. The red boxes suggest a possible extension of this array considering the numerous glider projects today.

Meanwhile, glider-ports or glider centres emerge in Australia, Canada, Europe, and the USA with the task of maintaining fleets of gliders in operations for such monitoring.

Research projects with gliders focus at the moment on the North and Equatorial Atlantic, the Pacific (south/north/west/east), the Mediterranean Sea, the Nordic Seas, the Solomon Sea, the Arctic, and the Antarctic. It is already a very valuable contribution to the global observing system by scanning as much as possible these regional seas, which can be very important for the global ocean and climate [52] and which are also highly sensitive to global change [53] but generally, solutions to sustain glider operations still have to be found.

Efforts to perform sustained observations with gliders are performed in many countries. In Australia, the establishment of Integrated Marine Observation System (IMOS) has resulted in deployments of the gliders around Australia through the Australian National Facility for Ocean Gliders (ANFOG) operating from the University of Western Australia. The goal is to provide a near-real time data stream from the continental shelf and slope waters around Australia. In particular, the gliders sample the main boundary current systems around Australia. These observations will be extended to include regions of the Southern Ocean to the south of Tasmania, and the Coral Sea between Great Barrier Reef and Papua New Guinea.
In Europe, Glider facilities in Cyprus, France (MOOSE (Mediterranean Ocean Observing System on Environment), and Spain (OceanBIT (BIT for Balearic Islands Technologies) ) are being set up to operate $>10$ glider tracks in the Mediterranean Sea [54]. Other European seas (Nordic Seas, Faroes, Irminger Sea) are concerned by glider initiatives in Germany, France, Norway, Spain and UK. Sampling more remote study areas induce some limitations in terms of logistics but through frameworks of collaborative process studies and research cruises, building on strong international partnerships, such as in the South-East Pacific (Peru) and in the tropical Atlantic (Cape Verde), glider observations are feasible in these areas of strong upwelling.

In the USA, there is a glider component in the Ocean Observing Initiative (OOI) for sites like Ocean Station PAPA, the Irminger Sea, the Argentine Basin, and off Chile. Each will have 3 gliders flying around the observatory [55]. There will also be 6 gliders each off the U.S. Pacific Northwest and the U.S. Middle Atlantic Bight as part of the coastal OOI effort. Gliders are already being deployed as part of the U.S. Integrated Ocean Observing System (IOOS) at various places along the western and eastern coasts of the USA and sustained glider deployments are carried out in the Solomon Sea. There are plans for operating gliders in the Gulf of Mexico and the Caribbean Sea as well as the Western Atlantic northeast of Brazil. These plans aim to 
improve estimates of the heat content of the upper ocean, forecasts of the intensity of hurricanes and the understanding of the regional system (including resources). The observations in the Gulf of Mexico and the Caribbean Sea are also useful in the context of plans for the Intra America Seas, which study interactions between the western hemisphere warm pool and weather and climate patterns.

Over time, the resulting glider array shown in Fig. 5 should be expanded into all regions where no regular observations of the upper 1000 to $1500 \mathrm{~m}$ are collected by profiling floats or other means that are very important for the global hydrography, circulation and biogeochemistry. This expansion will need to include:

- The sites of formation of deep and intermediate water, so important for the functioning of the ocean but poorly covered by floats and where important spring blooms occur during restratification;

- The boundary circulations. The western boundary region is generally very energetic and is critical for weather forecast [56]. Such regions are of large interest for the formation and intensification of tropical cyclones [57]. Also, collecting profiles in these regions will improve the estimates of the global ocean heat content significantly. The eastern boundary currents are very productive areas due to upwelling (Peru-Chile, African, etc.). Monitoring them is important for fisheries;

- A number of biogeochemical provinces, frontal areas, and persistent circulations, to better characterize the ocean circulation and the functioning of the marine ecosystem;

- The coastal area for cross-slope exchanges (link between the coastal environment and the open sea) and societal applications;

- The straits, which are suitable to put constraints on transports (overflows regions).

\subsection{Costs}

Presently, gliders cost about 100,000\$/Euro per unit to purchase, with running costs of about 5,000\$/Euro per unit per month (communications $2,000 \$$ /Euro per month, consumables, and other costs). Then, one has to include shipping costs and staff for a deployment of several months. Gliders require an expert team for the deployment/recovery and steering (one or several gliders), these are constraints to be taken into account when considering an expansion of glider activity. For such an expansion, the question is how many sustained glider campaigns or "repeat-section" (comprising a team of people and 2-4 instruments to cycle through use and maintenance) could we envision and afford?
Considering staff cost, the total effort for the scientific teams involved might be equivalent to deploy order of 10-50 additional profiling floats in the global system, including analysis of the data. However, this is really hard to estimate because of all uncertainties related to such activity; furthermore, one should also consider the required resources for maintenance and procurement.

Over 5 years, a glider repeat-section action with physical and biogeochemical sensors is certainly possible with 2-4 gliders $(100,000 \$$ /euro per unit, with a likely loss of $\sim 2$ gliders out of the $\sim 20$ successive required deployments) and incurring about $60,000 \$$ /euro per year for communications/repairs and $10,000 \$$ /euro (on average) per year for shipping/travel. This is about $650,000 \$$ /euro for a single, but sustained glider repeatsection during 5 years. However, this cost could soon decrease as the glider production increases and economies of scale may be realised.

On a per profile basis, gliders are about as expensive than Argo floats. If we include 5 person-years in that budget $(+300,000 \$ /$ euro $)$, the cost for one profile is about 100\$/euro (including biogeochemical parameters). Gliders do acquire a lot of profiles. Over 5 years a sustained glider section would have provided about 9125 profiles to $1000 \mathrm{~m}$ depth (5 profiles per day). Compare this with 150 profiles for one float (at $15,000 \$$ /euro for physical parameters only) requiring about $\sim 0.1$ person-years ( 5 person-years for 50 floats) giving about the same estimate of $\sim 100 \$ /$ euro per profile.

Sustained glider operation certainly requires more staff resource than 1 person per glider section, if not split in several operations. Here, we have assumed that a team of 3-5 persons (a critical size for the team) can manage to sustain 3-5 gliders sections with that budget of $650,000 \$$ /Euro per line over 5 years. Each glider line would represent an equivalent effort of $\sim 15-45$ floats (where the expected lifetime is 5 years) but note this glider/float ratio could decrease significantly, as the cost per unit for floats would increase with additional sensors for biogeochemical applications.

The glider community would like to use this technology to optimize the data coverage of the present global observing system. This requires about 100 people therefore about 20 sustained gliders projects within the next 5 years is feasible. As a community, a consensus should be reached to use gliders in about 20 important areas to contribute observations for the global functioning of the ocean (in regional seas, western/eastern boundary currents, and through OceanSITES (OCEAN Sustained Interdisciplinary Time series Environment observation System)). On this basis a rough estimate of the resources required for gliders at 
global scale would be about 13 million \$/euro for 5 years.

\section{THE WAY FORWARD}

The practical aspect of glider deployments/recoveries is a major problem and in this section, we tackle few perhaps exaggerated - ideas on how additional gliders could be deployed.

\subsection{From one research vessel to the other (or to shore)}

Among the next glider experiments, some will concentrate on fine scale phenomena and process studies. There are some plans in Europe to make gliders 'swarm' experiments in the Alboran Sea (Mediterranean) and in the Tropical Atlantic in 2010. A single glider carrying out a survey around, aside, and/or in-between shipborne profiles, could provide in real time good estimates of the variability in the area of interest of the cruise over scales ranging from few $\mathrm{km}$ to hundreds of $\mathrm{km}$. The goal of such 'swarm' experiments is to reach a level of accuracy never reached before for the estimation of the distribution of physical and biogeochemical properties over $0-1000 \mathrm{~m}$ and a few hundreds $\mathrm{km}$ horizontally. This does not immediately appear in the scope of a global observing system, but such an approach could benefit the global ocean observing system, if done in a systematic or manner over a number of cruises.

Why not deploy gliders between different ships whose schedules and intensions are known well in advance? Could we systematically arrange the ships tracks in such a way they are distant by about 2000km with 3 months between them? Such an approach would make relays possible. There is more flexibility than one would expect, as during long transit times small detour is possible at low cost, and only few people on-board for few hours would be necessary. For example, research vessels criss-cross many parts of the ocean to do targeted projects or to service moorings. These cruises could also be used to deploy (and recover) gliders.

\subsection{Glider sections from the shore to $\sim 100-1000 \mathrm{~km}$ offshore}

Repeating a section perpendicular to the isobaths from the coast is relatively easy and provides a number of profiles (from coastal to open sea) that are situated in important areas (for which one would need the most accurate estimates of the circulation and ecosystems). Any place in the ocean is less than $2700 \mathrm{~km}$ from land and if deployed worldwide at less than $1000 \mathrm{~km}$ apart from each other, that could really be consistent with an observing network at Argo scale (300km/10 days), if ones just thinks of glider sections split into segments with a length of about $300 \mathrm{~km}$ (each completed in $\sim 10$ days) with $\sim 50 / 250$ profiles distributed along the track, one can compare with Argo sampling in order to get an idea of the impact of such an initiative.

The concept of such endurance lines has been demonstrated, and should be developed wherever possible from the shelf environment to the open sea. In addition to 'small' scale information for regional forecasting models, gliders could then also provide a number of 'good' profiles at the boundaries between nested models, in order to be shared by regional and global models. That will likely help both of them to assess their budgets of mass, momentum, and fluxes of properties through these boundaries and make the link between coastal/regional and global observations.

The efforts for global observations with gliders should focus on choosing locations of such sections $(\sim 300 \mathrm{~km}$ long individually). Easy access to a glider-port is critical, but the sections should not be too close to each other, in order to maximize the space/time coverage, when taken together with the other global observing components. If one considers $120000 \mathrm{~km}$ of smoothed coast (or shelf break) for the earth ( $\sim 3$ times the earth's circumference), about 800 gliders (which is not so unrealistic!) would ensure that the boundary circulations and ecosystems would be sampled at much better resolution than the 'Argo scale'.

\subsection{The world tour by steps of $2000-6000 \mathrm{~km}$}

Here we consider a glider array similar to WOCE (World Ocean Circulation Experiment) for the first $1000 \mathrm{~m}$ of the upper ocean only, but repeated much more often. We would take advantage of coasts and islands and the global distribution of institutions and laboratories. Gliders could be deployed along transoceanic sections from one glider-port to the other (this would avoid the need for the glider to navigate the way back to its deployment location with the same batteries, which divides by two the possible range from the coast).

We have seen that the endurance and range of gliders can allow them to cross almost all the oceans in a few of months. Possible orders of magnitude (with some safety) are $\sim 3-8$ months to complete a section of 2000$6000 \mathrm{~km}$ length. Several gliders following each other along such a section would make much better sampling: two gliders would consequently make a repeat rate of 1.5-2.5 months, for three gliders the repeat rate is $0.5-1$ month and so on. This approach is robust because it odes not cause big problems if one glider fails, since 510 gliders have the same role: the overall mission would be completed.

In fact, trans-Atlantic glider shipping costs around $2,000 \$$ /euro ( $2 \%$ of the cost of the platform) hence the return via classical shipping lines could be envisaged 
seriously. However, it can take more time than one would expect - perhaps months when troubles with customs occur. That require additional gliders in a fleet (but ones that are not at sea!) to provide a buffer for such delays. It would be better if the gliders were serviced where they can be recovered and sent back from there, or sent to another place, flying through the ocean. We could even dream of a glider world tour, one single glider completing it, step-by-step (i.e. about $40,000 \mathrm{~km}$ with multiple deployments in about 3 years). For these reasons, further developments should encompass logistical support between laboratories to share refurbishments and spares, and even to exchange whole glider systems in a legally secure way for the benefit of a global ocean observing system. Managing the same repeat-section by two small teams from each part of a basin is easier since it requires locally less manpower as minimal infrastructures are provides at each end.

\section{CONCLUSION}

We really are about to enter into a new era in oceanography with gliders providing many contributions to sustained ocean observations in the coming decade. We are mainly limited by our imagination and available funding. Anticipated advances in biogeochemical sensors, payload capacity, battery duration, and ease-of-use will expand our ability to use gliders to monitor the physical and biogeochemical state of regional seas and boundary current systems (and marine protected areas, in particular), to understand responses and links to climate variability. High-resolution physical and biogeochemical data in these regions from gliders in combination with the other components of the global observing system, will, without any doubt, allow us to fulfill far more objectives related to societal aspects (including marine security and "green" objectives) than is possible today. We anticipate that the glider component, which has relevance to process studies and monitoring, will be used actively, and in many places in the next decade will start to fill the gaps and to optimize the global network for the benefit for all observing and forecasting systems -global and regional/coastal onesand all related applications.

In this context, we would strongly recommend for the next 10 years:

1. the formation of the global glider system as an extension of the present global observing system;

2. the adoption of standards and a "ARGO" like data system for gliders;
3. the target of about 20 standard section in continuous occupation;

4. the setup of a network of shared resources and expertise; in order to:

5. distinguish between climate and process and NWP (National Weather Prediction) objectives;

6. establish the adoption of a common and accessible portal for glider data.

\section{REFERENCES}

1. Claustre, H. \& Co-Authors (2010). "Bio-Optical Profiling Floats as New Observational Tools for Biogeochemical and Ecosystem Studies: Potential Synergies with Ocean Color Remote Sensing." in these proceedings (Vol. 2), doi:10.5270/OceanObs09.cwp.17.

2. Balmaseda, M. \& Co-Authors (2010). "Initialization for Seasonal and Decadal Forecasts" in these proceedings (Vol. 2), doi:10.5270/OceanObs09.cwp.02.

3. Stommel, H., (1989). The Slocum Mission. Oceanography, April 1989, 22-25

4. Griffiths, G., Russ, D., Eriksen, C., Marchand, P., Frye, D. \& T. Dickey, (1999). Towards new platform technology for sustained observations, OceanObs'99.

5. Davis R., Eriksen C. \& C. Jones (2002). Autonomous Buoyancy-driven underwater gliders, in 'The Technology and Applications of Autonomous Underwater Vehicles', G. Griffiths, ed., Taylor and Francis, London, 2002

6. Rudnick D., Davis R., Eriksen C., Frantantoni D. \& M.-J. Perry, (2004) "Underwater Gliders for Ocean Research," Marine Technology Journal, vol. 38, no. 1, Dec., pp. 48-59, 2004.

7. Webb, Doug C., (1986). Thermal Engine and Glider entries, Notebook No. 2, pg. 254 - 255, 2/8/86

8. Simonetti P., (1992). Slocum Glider: Design and 1991 Field Trials, Office of Naval Technology Contract N00014-90C-0098 Report, 1992.

9. Testor P., Send U., Zappala G., Jones C., Terre T., Azzaro M., Casas B., Lherminier P., Petit de la Villeon L. Alvarez A., Begler C., Karstensen J. \& T. Csernok, (2005). New capabilities offered by gliders, MERSEA annual meeting, Toulouse, France, March 2005.

10. Hátún, H., Eriksen, C.C.\& P.B. Rhines (2007). Buoyant eddies entering the Labrador Sea observed with gliders and altimetry. J. Phys. Oceanogr. 37:2,8382,854

11. Davis, R., Ohman, M. D., Rudnick, D.L., Sherman J. \& B. Hodges, (2008). Glider surveillance of physics and biology in the southern California Current System, Limnol. Oceanogr., 53(5, part 2), 2008, 2151-2168. 
12. Eriksen, C.C. \& Rhines, P.B. (2008). Convective to gyrescale dynamics: Seaglider campaigns in the Labrador Sea 2003-2005. Chapter 25 in Arctic-Subarctic Ocean Fluxes: Defining the Role of the Northern Seas in Climate. R. Dickson, J. Meincke, and P. Rhines, eds, Springer-Verlag.

13. Glenn S., Jones, C., Twardowski, M., Bowers, L., Kerfoot, J., Kohut, J., Webb, D. \& O. Schofield (2008). Glider observations of sediment resuspension in a Middle Atlantic Bight fall transition storm. Limnol. Oceanogr., 53(5, part 2), 2008, 2180-2196

14. Gourdeau, L., Kessler, W. S., Davis, R. E., Sherman, J., Maes, C.\& E. Kestenare,(2008). Zonal jets entering the Coral Sea, J. Phys. Oceanogr., Vol. 38, No. 3, 714-724.

15. Nicholson, D., Emerson, S. \& C.C. Eriksen, (2008). net community production in the deep euphotic zone of the subtropical North Pacific gyre from glider surveys. Limnol. Oceanogr., 53(5, part 2), 2008, 2226-2236

16. Niewiadomska, K., Claustre, H., Prieur, L. \& F. d'Ortenzio, (2008). Submesoscale physicalbiogeochemical coupling across the Ligurian Current (northwestern Mediterranean) using a bio-optical glider, Limnology and Oceanography, 53, 2210-2225.

17. Perry, M.J., Sackman, B.S., Eriksen, C.C. \& C.M. Lee (2008). Seaglider observations of blooms and subsurface chlorophyll maxima off the Washington coast. Limnol. Oceanogr., 53(5, part 2), 2008, 21692179

18. Martin, J. P., C. M. Lee, C. C. Eriksen, C. Ladd, and N. B. Kachel (2009), Glider observations of kinematics in a Gulf of Alaska eddy, J. Geophys. Res., 114, C12021, doi:10.1029/2008JC005231

19. Ruiz, S., Pascual, A., Garau, B., Faugere, Y., Alvarez, A. and J. Tintoré, (2009). Mesoscale dynamics of the Balearic front integrating glider, ship and satellite data, J. Mar. Sys., [in press], doi:10.1016/j.jmarsys.2009.01.007.

20. Baumgartner, M. and D. Fratantoni, (2008). Diel periodicity in both sei whale vocalization rates and the vertical migration of their copepod prey observed from ocean gliders, Limnol. Oceanogr., 53(5, part 2), 2008, 2151-2168.

21. Castelao, R., Glenn, S., Schofield, O., Chant, R., Wilkin, J. and J. Kohut (2008). Seasonal evolution of hydrographic fields in the central Middle Atlantic Bight from glider observations. Geophys. Res. Let., doi:10.1029/2007GL032335.

22. Nevala, A. (2005). A Glide Across the Gulf Stream, WHOI Oceanus, March 2005

23. Leonard, N.E., Paley, D.A., Lekien, F., Sepulchre, R., Fratantoni, D.M. and R.E. Davis (2007). Collective Motion, Sensor Networks, and Ocean Sampling, Proceedings of the IEEE, 95, 1,48-74, doi:10.1109/JPROC.2006.887295.
24. Testor P., Mortier, L., Send, U., Davis, R., Smeed, D., Merckelbach, L., Alvarez, A., Tintore, J., Lherminier, P., Terre, T., Krahmann, G., Karstensen, J., Claustre, H., Naudin, J.-J., Rigaud, V., Carval, T., Petit de la Villeon, L., Jones, C. \& J. Sherman (2007). European Gliding Observatories (EGO), Coriolis Newsletter, October 2007.

25. Testor P., Mortier, L., Lheveder, B., Taillandier, V., Send, U., Smeed, D., Merckelbach, L., Alvarez, A., Tintore, J., Casas, B., Ruiz, S., Lherminier, P., Terre, T., Krahmann, G., Karstensen, J., Bourrin, F., Claustre, H., Naudin, J.-J., Rigaud, V., Carval, T., Petit de la Villeon, L., Jones, C. \& J. Sherman (2008). Regional in-situ observatory: glider observations in the northwestern Mediterranean Sea in winter 2008 (EGO), GODAE final symposium, Nice, France, November 2008.

26. Testor, P. (2006). The development of the glider system, MERSEA annual meeting, London, UK, March 2006.

27. Fiorelli, E., Leonard, N.E., Bhatta, P., Paley, D., Bachmayer, R. \& D.M. Fratantoni, (2004). MultiAUV Control and Adaptive Sampling in Monterey Bay, Proceedings of the IEEE Autonomous Underwater Vehicles 2004: Workshop on Multiple AUV Operations (AUV04), Sebasco, ME, June 2004

28. Davis R., Leonard, N. E. \& D. M. Fratantoni, (2009). Routing strategies for underwater gliders, Deep Sea Res. Part II, Volume 56, Issues 3-5, February 2009, Pages 173-187.

29. Bhatta, P., Fiorelli, E., Lekien, F., Leonard, N. E., Paley, D. A., Zhang, F., Bachmayer, R., Davis, R. E., Fratantoni, D., \& Sepulchre, R. (2005). Coordination of an underwater fleet for adaptive sampling. In International Workshop on Underwater Robotics, pages 61-69.

30. Lekien, F., Mortier, L., \& P. Testor, (2008). Glider Coordinated Control and Lagrangian Coherent Structures, NGCUV08, Killaloe, Ireland, April 2008.

31. Garau B., Alvarez, A. \& G. Oliver. (2005). Path planning of autonomous underwater vehicles in current fields with complex spatial variability: an A* approach. Proceedings of the 2005 IEEE International Conference on Robotics and Automation, 195-199

32. Garau, B., Alvarez, A. \& G. Oliver, (2006). AUV navigation through turbulent ocean environments supported by onboard H-ADCP. Proceedings of the 2006 IEEE International Conference on Robotics and Automation, 3556-3561

33. S. Ruiz, A. Pascual, B. Garau, I. Pujol, and J. Tintoré (2009), Geophys. Res. Lett., 36, L14607, doi:10.1029/2009GL038569

34. Le Quéré, C. \& Co-Authors (2010). "Observational Needs of Dynamic Green Ocean Models" in these proceedings (Vol. 2), doi:10.5270/OceanObs09.cwp.56. 
35. Heimbach, P. \& Co-Authors (2010). "Observational Requirements for Global-Scale Ocean Climate Analysis: Lessons from Ocean State Estimation" in these proceedings (Vol. 2), doi:10.5270/OceanObs09.cwp.42.

36. Levy M., Klein P. \& A.-M. Treguier, (2001). Impacts of sub-mesoscale physics on phytoplankton production and subduction, J. Mar. Res., 59,535-565.

37. Mariano A.J., Chin M. And T. M. Özgökmen, (2003). Stochastic boundary conditions for coastal flow modeling. Geophys. Res. Lett., 30(9), 1457-1460.

38. Shulman I., Rowley C., Anderson S., DeRada S., Kindle J., Martin P., Doyle J., Cummings J., Ramp S., Chavez F., Fratantoni D. and R. Davis, (2009). Impact of glider data assimilation on the Monterey Bay model, Deep Sea Res., Volume 56, Issues 3-5, February 2009, Pages 188-198 AOSN II: The Science and Technology of an Autonomous Ocean Sampling Network

39. Dobricic, S., N. Pinardi, P. Testor and U. Send, (2010). Impact of data assimilation of glider observations in the Ionian Sea (Eastern Mediterranean), Dynamics of Atmospheres and Oceans, 50, 78-92, doi:10.1016/j.dynatmoce.2010.01.001.

40. Taillandier V., A. Griffa, P.-M. Poulain and K. Beranger, (2006). Assimilation of ARGO float positions in the North Western Mediterranean Sea and impact on ocean simulations, Geophys. Res. Let., L11604

41. Garau et al, (2009). Glider salinity calibration, in preparation.

42. Bork K., Karstensen J. Visbeck M. Zimmermann A., (2008). The Legal Regulation of Floats and Gliders In Quest of a new Regime?, Ocean Development \& international law, 39:298-328, 2008. doi:10.1080/00908320802235338.

43. Lee, C. \& Co-Authors (2010). "Autonomous Platforms in the Arctic Observing Network" in these proceedings (Vol. 2), doi:10.5270/OceanObs09.cwp.54.

44. Perry M. J., Briggs N., Gray A., Lee C., Rehm E., D'Asaro E., Gudmundsson K., Kallin E., Lampitt R., Poulton N., Rynearson T., Sieracki M., (2008). Optical observations of large diatoms and sinking particles during the North Atlantic Spring Bloom made from seagliders, floats and a ship. Ocean Optics 2008, Italy.

45. Gobat J. and C. Lee, (2006). Developments in acoustic navigation and communication for high-latitude ocean research, $A G U 2006$

46. Send, U. \& Co-Authors (2010). "OceanSITES" in these proceedings (Vol. 2), doi:10.5270/OceanObs09.cwp.79.

47. Osse, T.J. \& C.C. Eriksen (2007). The Deepglider: A Full Ocean Depth Glider for Oceanographic Research, OCEANS 2007, 1-12, doi:10.1109/OCEANS.2007.4449125.
48. Adornato, L. \& Co-Authors (2010). "In Situ Nutrient Sensors for Ocean Observing Systems" in these proceedings (Vol. 2), doi:10.5270/OceanObs09.cwp.01.

49. L'Hévéder, B., Lellouche, J.-M., Lherminier, P., Mortier, L., Terre, T., Testor, P. \& G. Vinay, (2009). Operational Forecast of Glider trajectories during EGO 2008 operations in the Mediterranean Sea using Mercator Ocean Forecast, MERCATOR Newsletter 32.

50. Oke, P. \& Co-Authors (2010). "Observational Requirements of GODAE Systems" in these proceedings (Vol. 2), doi:10.5270/OceanObs09.cwp.67.

51. Gruber, N., Doney, S.C., Emerson, S.R., Gilbert, D., Kobayashi, T., Koertzinger, A., Johnson, G., Johnson, S.K., Riser, S.C.\& O. Ulloa, (2007). the Argo-oxygen program, white paper for Argo Steering Committee.

52. Johnson R.G. (1997). Climate control needs a dam at the strait of Gibraltar, Eos Vol. 78, No. 27, July 8, 1997, pp. $277,280-81$.

53. Cacho, I., Grimalt, J.O. \& M. Canals, (2002). Response of the Western Mediterranean Sea to rapid climatic variability during the last 50,000 years: a molecular biomarker approach, J. Mar. Sys., 33-34,253-272.

54. Mortier, L. \& Testor, P. (2008). In situ remote sensing with autonomous platforms: a new paradigm for observing the ocean interior, Towards an integrated system of Mediterranean marine observatories, CIESM workshop monographs, La Spezia, 16-19 January 2008.

55. Send, U. \& Co-Authors (2010). "A Global Boundary Current Circulation Observing Network" in these proceedings (Vol. 2), doi:10.5270/OceanObs09.cwp.78.

56. Goni, G. \& Co-Authors (2010). "The Ocean Observing System for Tropical Cyclone Intensification Forecasts and Studies" in these proceedings (Vol. 2), doi:10.5270/OceanObs09.cwp.36.

57. Cronin, M. \& Co-Authors (2010). "Monitoring Ocean Atmosphere Interactions in Western Boundary Current Extensions" in these proceedings (Vol. 2), doi:10.5270/OceanObs09.cwp.20. 